\title{
The Title: Academies football as a source of self-financing of sports clubs (case study)
}

Abd alaa mohey : Lecture, sports administration \& recreation, faculty of physical education for men, Alexandria University, Egypt

\section{Research problem}

Fund is an essential factor in all physical activity elements in the institution, and all these elements are engaged with the funding process, which assists in the implementation of placed plans is order to promote various sports items. (15: 76)

Money consider as essential as blood for living organisms and the flow of the money to the Organization and its distribution indicates the competitive position of the Organization and enhance its services.(2:273)

So Money is the nerve of institutions and bodies which helps them to achieve their objectives, since these institutions will not achieve success unless they have necessary financial resources to manage their activities and then achieve their desired goals.(21:77)

Samir Abdul Hameed (1999) Indicates that sports bodies suffer a lot from financial crises because of the raise of outcomes than incomes, which represents a major impediment in sport level progress, as that sport field became a burden on country resources in which they are supported within the available and became insufficient to achieve the essential requirements for these institutions success, as there is a reduction in the rate of financial contributions, difficulty to afford, its instability and lack in funding resources. (14: 79) Sports institutions depends on budget accumulation in the implementation of their programs to achieve their objectives, and our sports institutions suffer from insufficient efforts to increase fund.(18: 198)

Sports clubs have the right to develop their resources through the establishment of sport academies or schools within the Club's headquarters and branches, and the establishment of academies outside its headquarters shall obtain a permit from the competent Federation game that should have financial accounts for these sport schools outside the Club and accredit the receipts from the competent administrative authority.(20:30) 
Al-Ahly Club established the soccer Academy in 2006 and various branches have been opened outside the Club, that academy season begins in July and ends in April of the following year.(4:45)

The popularity of soccer, spread of developed stadiums and multitude of unofficial or personal academies all that consider as an opportunity for sports clubs to invest in establishing either internal or external sports academies, which can contribute in the development of Club's financial resources as well as discovering many talented and escalate them to junior teams then the first team or players marketing to achieve financial returns to the Club, and the research problem appears through the researcher experience as a member of the marketing Committee at the Ithad Alex Club, and the Manager of Zamalek Football Academy in Alexandria where he recognized that there is no existence of outside clubs Academies outside their governorates which leads to the loss of investments and financial opportunities for the clubs which stimulate the researcher to apply this study in order to highlight the importance of the financial role for soccer academies, and the researcher took Al-Ahly club soccer academy as a case study as it considers as the first club that established external Academies since 2007 and still expanding constantly, whether at the local or regional level outside the Arabic Republic of Egypt.

Therefore, the present study tries to identify the role of soccer academies in the development of financial resources for sports clubs

\section{Study objectives :}

The study aims to identify the role of soccer academies in the development of Club resources through the identification of :

1. Financial returns of soccer academies in Egyptian clubs.

2. Percentage of financial returns contribution for soccer academies in clubs revenues.

3. The rate of financial returns development for soccer academies.

\section{Study questionnaire}


1. What is the value of financial returns for Soccer academies in Egyptian clubs?

2. What is the percentage of contribution for soccer academies incomes in club revenue?

3. What is the rate of financial income development for soccer academies?

\section{Study procedures}

\section{Study method}

the researcher used the analytical approach with case study method.

Study community : Egyptian sports clubs .

Research Sample: al- ahly club

\section{Data collection tools}

The researcher used accredited documents adopted by Al-ahly club consisted of the budget and the final account for the years 2007 to 2014

\section{Results presentation}

The researcher will present and discuss the results consistent with the research objectives . 
Statistical descriptions

Table (1)

Statistical semantics for research sample in subjective fund variables

$\mathbf{N}=8$

\begin{tabular}{c||c|c|c|c|c|c}
\hline \hline $\begin{array}{c}\text { Statistical } \\
\text { Semantics }\end{array}$ & Lowest value & Biggest value & $\begin{array}{c}\text { Arithmetic } \\
\text { mean }\end{array}$ & Median & $\begin{array}{c}\text { Standard } \\
\text { deviation }\end{array}$ & $\begin{array}{c}\text { Torsion } \\
\text { coefficient }\end{array}$ \\
\hline variables & & & & & & \\
\hline $\begin{array}{c}\text { Academy incomes } \\
\text { Academy outcomes }\end{array}$ & 2758653 & 5530716 & 4466658 & 4785688 & 925237 & $0.943-$ \\
\cline { 2 - 7 } $\begin{array}{c}\text { Total budget } \\
\text { incomes for the } \\
\text { same year }\end{array}$ & 152285644 & 252642618 & 181763091 & 171113274 & 32326477 & 1.839 \\
\hline \multirow{2}{*}{\begin{tabular}{c} 
No of participants \\
\cline { 2 - 7 }
\end{tabular}} & 2406 & 4780 & 3748 & 4189 & 1037 & $0.458-$ \\
\hline \hline
\end{tabular}

Table (1) shows that the overall study sample data is moderate and shows normal distribution for the sample, the coefficient values ranging between $(-0.943$ to 1.839$)$. These values near to zero, which indicates to recognize equinoctial distribution format.

presentation of statistical semantics and results comparison between incomes and outcomes in self-financing

Table (2) the differences between incomes and outcomes from (2007-2014)

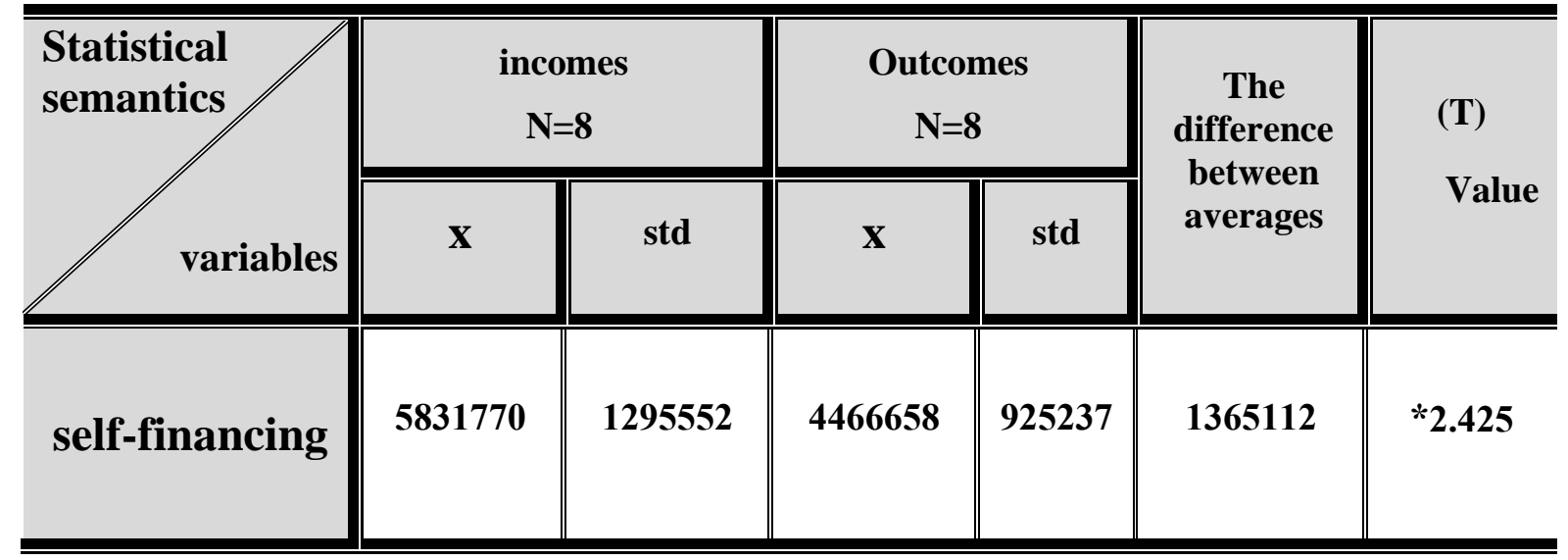

*Significant at $0.05=2.145$ 
Table (3)

Indication of differences amount between incomes and outcomes

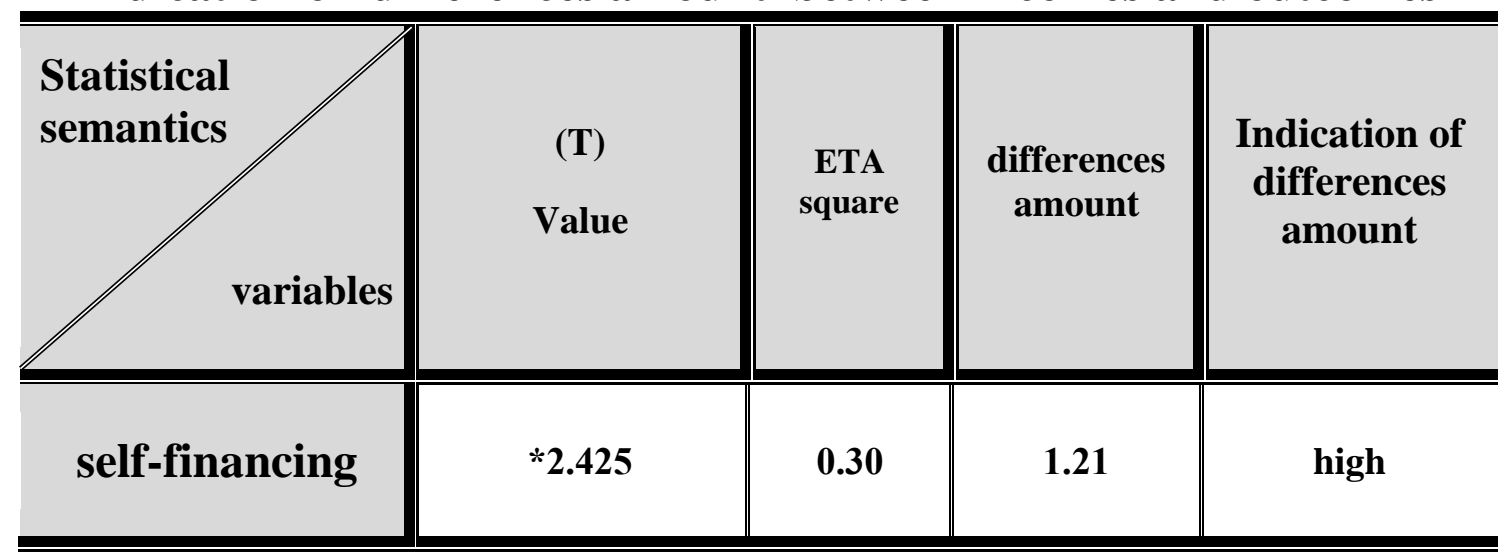

Significance of effect size: * less than 0.5 (low) $* 0.5$ to 0.8 (average) * greater than 0.8 (high)

Table (2), (3) and figure (1) for semantic and statistical results of the comparison between incomes and outcomes in self-financing shows statistically significant differences at level (0.05) for incomes in which value $(\mathrm{T})$ calculated is greater than the value (T) tabled at level (0.05)

illustrates Percentage of contribution of incomes in relation to the total budget outcomes for the same year

\begin{tabular}{|c|c|c|c|}
\hline Year & $\begin{array}{c}\text { Academy } \\
\text { incomes }\end{array}$ & $\begin{array}{c}\text { Total budget incomes for the } \\
\text { same year }\end{array}$ & $\begin{array}{c}\text { Percentage of } \\
\text { \%contribution }\end{array}$ \\
\hline 2007 & 5554067 & 169142883 & 3.284 \\
\hline 2008 & 6246082 & 162589825 & 3.842 \\
\hline 2009 & 7247125 & 175997413 & 4.118 \\
\hline 2010 & 6035695 & 152285644 & 3.963 \\
\hline 2011 & 7780960 & 173083664 & 4.495 \\
\hline 2012 & 5445084 & 164496000 & 3.310 \\
\hline 2013 & 4193495 & 203866681 & 2.057 \\
\hline 2014 & 4151655 & 252642618 & 1.643 \\
\hline Average & 5831770.4 & 181763091 & 3.208 \\
\hline
\end{tabular}


ratio of outcomes to incomes of same year

\begin{tabular}{|c|c|c|c|c|}
\hline Year & $\begin{array}{c}\text { Academy } \\
\text { incomes }\end{array}$ & outcomes & $\begin{array}{c}\text { The percentage of } \\
\text { academy outcomes } \\
\text { compared to } \\
\text { incomes }\end{array}$ & Net profit \\
\hline 2007 & 5554067 & 2758653 & $\% 49.669$ & $\% 550.331$ \\
\hline 2008 & 6246082 & 5530716 & $\% 88.547$ & $\% 11.453$ \\
\hline 2009 & 7247125 & 5244011 & $\% 72.360$ & $\% 27.64$ \\
\hline 2010 & 6035695 & 4915946 & $\% 81.448$ & $\% 18.552$ \\
\hline 2011 & 7780960 & 4857718 & $\% 62.431$ & $\% 37.569$ \\
\hline 2012 & 5445084 & 4713658 & $\% 86.567$ & $\% 13.433$ \\
\hline 2013 & 4193495 & 4154402 & $\% 99.068$ & $\% 0.932$ \\
\hline 2014 & 4151655 & 3558163 & $\% 85.705$ & $\% 14.295$ \\
\hline Average & $\mathbf{5 8 3 1 7 7 0 . 4}$ & 4466658.4 & $\% 76.592$ & $\% 23.408$ \\
\hline
\end{tabular}

\section{Results Discussions}

It is seen from the previous offer for comparing incomes and outcomes in self-financing and differences amounts of average income for the period 2007-2014 reached (5831770 million pounds) while the average academy expenses during that period was $(4,466,658$ million pounds) with an increase in financial income that amounted $(1,365,112$ million pounds) for incomes where the value $(T)$ calculated is higher than value $(T)$ table which indicates moral differences for incomes than outcomes and the statistical differences amounted (high).

It is clear from for the proportions of incomes contribution in relation to the total budget income for the same year, the average percentage of contribution to the incomes of the soccer Academy in total budgetary incomes was $(3.208 \%)$ and the highest contributor percentage in 2011 was $4.495 \%$ percent while the lowest percentage in 2014 was $1.643 \%$, that declination in $2013 / 214$ because of inactivity of one of the most important main branches (Alexandria branch), while the researcher illustrates the development of the percentage of contribute since the beginning of the establishment of the Academy to the expanding numbers of foreign branches of the Academy which reached 8 branches in the 
provinces which contributes to increase the financial resources of the Academy

It is clear from for the academy ratio between expenses and incomes for the same year that the average net profit for the academic period 2007 to 2014 reached $23.408 \%$ and achieved the highest profit in 2007 was $50.331 \%$ as a result of higher incomes and lower expenses for the Academy, as the second year with higher Participants numbers and lower financial costs specially in renting play grounds, while the lowest profit was in 2014 which reached $0.932 \%$, the researcher returns that to the change in the financial regulations for clubs in accordance with statutes to start in January and ends in December, which leaded to change the financial systems for the preparation of budgets and final accounts in sports clubs.

It is clear from the previous presentation of the study results that soccer academies contribute effectively in clubs budget incomes and that what's shown in tables which indicates the importance of establishing soccer academies which consider a source of selffinancing for sports clubs which contribute in the development of sports clubs sources, therefore clubs should depends on investing its own resources in order to achieve their needs and requirements which agrees with the statutes for clubs to develop its financial resources Through the establishment of internal and external soccer academies.

Samir Abdel Hamid (1999) also refers that financial crises suffered by sports clubs because of the financial requirements for the training process necessitated to search for a new way to provide material resources to raise the level of sports competitions . (20:30)

Hassan El-Shafei (2006) confirms that sports organizations should rely on their own resources and their ability to develop these resources .$(12: 32)$

Abdullah mohey study (2007) (16) indicates that there are multiple activities and funding methods must be done by sports clubs to develop their financial resources such as soccer academies.

studies results for Abu Bakr Yehia Sedek Omar

(2005) ,Muhammad Alnemir Hassan (2010) , Faisal Abdullah Al-Amiri (2012) , Ashraf Mahmoud Hussein Al-ajili (1999) According to support sports clubs and the need to pay attention to subjective 
resources and work to find new, multiple and continuous funding resources. And The importance of publishing school ages for soccer with legal controls regulates its work, organize a fixed annual competition for these schools across

and studies results for Daniel Kraker (1995), Kennett P.A (1997) ,Pitts \& Astolor (1996) According to creating marketing opportunities for small clubs could solve the chronic economic problems faced by these clubs.

EU federation for soccer report points that $60 \%$ of European clubs considers that Soccer Academy is the source of income and the goal is creating economic value so that investments in Youth Academy offer a good return and its necessary for each club to increase investment in youth academies and make it an essential pillar for sustainable growth in soccer clubs. (28:54)

In this regard, Mohamad Mohamad Abdel Kader (2005) (23) study results indicates that there are financial goals the Club seeks to provide income sources for the Club.

This is consistent with the decision of the Association of the Professional League clubs in Germany in 2001 requiring all clubs to establish soccer youth academies, which contributed to the great success of the German team as seen in the 2010 World Cup where the average age of players was less than 25 years, all that was a result of these academies hard working since the establishment of academies in 2001 till 2010 , clubs spent nearly 520 million euros in practicing of youth soccer . (30:11)

This is consistent with what Deloitte mentioned that there is a strong system for Soccer academies in European clubs through selecting talents and develops them for the first team. And provide financial income from increased investments offered by clubs in academies. (27:98)

As Apilad Crestal (2003) (25) study "challenges of funding for sports clubs" points that support offered for sports clubs are few which impact negatively on sports activities so it requires the search for new funding opportunities

And The Researcher finds that Egyptian sports clubs should study the European regulations for soccer clubs in the field of soccer academies as a field for investments and financial resource development. 
In this regard Saad Ahmed SHalaby (2006) indicates that the clubs incomes can be increased through good marketing while increasing its chances to obtain funding opportunities through marketing activities as compared to excellence is one of the methods that reflect the efficiency of the current situation of the management of marketing activities in Egyptian clubs (13:3)

Birkbeck Sport Business report Research Centre (2009) Report indicates that many European sports clubs established soccer academies throughout the world to search for future talents and achieve financial returns by selling players Where there are major types of soccer Academies that works in Africa. First African academies, organized and managed by the African clubs or national federations and second the Afro-European academies, which usually takes three forms: the first involves an European club to establish a private academy belongs to it in Africa as a foreign site and the second includes a partnership between African clubs or an academy and an European team, and the third includes taking the European club a dominant space in the African club . (24:63)

\section{Conclusions}

In the light of the results concluded from the financial analysis for Alahly club budgets for the period 2007-2014 shows :

1. Increase overall incomes than outcomes for the period (2007-2014) with a financial amount $\$ 1,365,112$ million pounds

2. Soccer academies contribute with inconstant positive financial ratios in the Club annual budgets.

3. The soccer Academy achieves an annual profit since it was established.

\section{Recommendations}

1. The importance to the rationalization of outcomes for the Academy to increase the proportion of net profit

2. Consider to open new branches inside and outside

3. Sports clubs should be aware to establish internal and external soccer academies 
4. The Awareness to the financial analysis process for soccer academies as a step to make investment decisions for the development of the resources of the Club

5. Clubs should be coordinated with the Ministry of youth and sports to exploit developed playgrounds youth centers for establishing football academies

6. The need for the establishment of specialized departments for soccer academies

The need to coordinate with marketing departments to develop marketing plans for soccer academies 
References :-

* First : Arabic references :
1) Abu Bakr Yehia Elsedek
2) Ahmad Moustafa Khater et. Al.
3) Ashraf Mahmoud Alegely

4) Financial report

5) Financial report

6) Financial report

7) Financial report

8) Financial report

9) Financial report

10) Financial report
:Essential resistors for soccer schools in Sudan, unpublished MD thesis, Faculty of physical education,Khartoum university , 2005

:Management in social institutions, university house, 2001.

:Investment Obstacles in sports field in Arabic Republic of Egypt , unpublished MD thesis, Faculty of physical education for men ,Helwan university , cairo , 1999

:Board of Directors report, budget, final accounts, financial report and draft budget for the financial year 2007

:Board of Directors report, budget, final accounts, financial report and draft budget for the financial year 2008

:Board of Directors report, budget , final accounts, financial report and draft budget for the financial year 2009

:Board of Directors report, budget, final accounts, financial report and draft budget for the financial year 2010

:Board of Directors report, budget, final accounts, financial report and draft budget for the financial year 2011

:Board of Directors report, budget, final accounts, financial report and draft budget for the financial year 2012

:Board of Directors report, budget, final accounts, financial report and draft 
11) Financial report

12)

Hassan Ahmad Elshafey

13)

Saad Ahmad

Shalaby

14) Samir Abd Elhameed

15)

Saber Abd

Elmeniem Hassan

16)

Abdullah Mohamad Mohey

17)

Abdullah Mohamad Mohey

18) Essam Badawy

19)

Faysal Abdullah AlEmery budget for the financial year 2013

:Board of Directors report, budget, final accounts, financial report and draft budget for the financial year 2014

:Marketing and investment in physical education and sports, El Wafaa publishing house , 2006

:Marketing and investments fields at Egyptian and European clubs (analysis study) , $9^{\text {th }}$ international scientific conference for physical education and sports, 8-10 Nov. 2006

:Modern sports institution management and its applications, Almaraf facility , Alexandria , 1999

:The future of Olympic Games in international changes conditions, unpublished phd thesis, faculty of physical education for men , Helwan university , Cairo , 2001

:Strategy to operationalize self-financing sources at some sports clubs in Arabic Republic of Egypt, unpublished phd thesis, faculty of physical education for boys . Alex university , 2011

:A proposed model for marketing performance assessment criteria for some sports clubs in Arabic Republic of Egypt , unpublished MD thesis , faculty of physical education for boys . Alex university , 2007

: Encyclopedia of management and administration in physical education and sport , First addition

: The reality of funding sports clubs in Saudi Arabia between the public and 
private sector and their role in sports and security development from the prospective of official sports clubs in Riyadh, MD thesis Nayef university for security science, Faculty of post graduate , management science dep., 2012

20)

Decision of sports : List Statutes for clubs 2013

Minister

21) Kamal Ahmad

Darwish

22)

Mohamad EINamir Hassan

: Sports management fundementals and applications, Cairo, third edition , 1996

:Soccer elite clubs funding " sources amount and relationship arranged in 2010", unpublished MD thesis, faculty of physical education, Sudan university for science and technology , 2010

: A Model for marketing management in

23)

Mohamad Mohamad Abd ElKader sports clubs, unpublished MD thesis, faculty of physical education for men , Helwan university, 2005

\section{Second : Foreign references :}

Birkbeck

24)

Business

Research

Series

25) Crystal Apilad

26) Dan iel Draker

27) Deloitte2015

28) ECA Report2012
: Sports club challenges u.s.a funding, Amazon. Com, western herald, October. 30, 2003, U.S.A.

: The Economics of Pro Sports, Program for The Institute for Local Self, Reliance, July, 1995

Annual Review of Football Finance 2015

ECA Report on Youth Academies 2012 
29) Kennette. P.A.

: Marketing segmentation in the sport industry, international sports journal, (1), refs (16). U.S.A. 1997

Periodic report to : 10 Years of academies Talent pools of

30) theGerman Football top-level German football Association in 2010

Fudamentals of sports, marketing fitness

31) Pitts \& Astolor, D.K information technology, I n c morgan town U.S.A. 1999 